\title{
Interstitial 4q Deletion and Isodicentric Y-Chromosome in a Patient with Dysmorphic Features
}

\author{
T.I. Mancini M.M. Oliveira A.R.N. Dutra A.B.A.Perez R.M. Minillo S.S. Takeno \\ M.I. Melaragno \\ Genetics Division, Department of Morphology and Genetics, Universidade Federal de São Paulo, São Paulo, Brazil
}

\section{Key Words \\ BAC $\cdot 4 q$ deletion $\cdot$ Dysmorphic features $\cdot$ FISH $\cdot$ Isodicentric $Y \cdot$ Karyotype $\cdot$ Single nucleotide polymorphism}

\begin{abstract}
We present a 2-year-old boy with a de novo 46,XY,idic(Y) (q11.221),del(4)(q26q31.1) karyotype. G-banding, FISH, MLPA, and SNP-array techniques were used to characterize the $24-\mathrm{Mb}$ deletion in $4 \mathrm{q}$ and the breakpoint in the isodicentric Y-chromosome region between 15,982,252 and $15,989,842 \mathrm{bp}$. The patient presented with mild facial dysmorphism, hemangioma, mild frontal cerebral atrophy, and Dandy-Walker variant. Essentially, this case reveals that patients can present more complex genomic imbalances than initially suspected.

Copyright $\odot 2012$ S. Karger AG, Basel
\end{abstract}

Structural chromosome aberrations are known to cause developmental delay, dysmorphism and multiple congenital malformations. Some aberrations, including translocations, isochromosomes, and large deletions, can usually be identified by G-banding. However, some ge- nomic imbalances are harder to characterize using classical cytogenetics, therefore requiring molecular techniques [Gu et al., 2008]. Fluorescence in situ hybridization (FISH) detects specific structural chromosome abnormalities, but it is relatively labor-intensive and its resolution in diagnostics is limited by the size of the probe [Gijsbers and Ruivenkamp, 2011]. Another technique that can be used is multiplex ligation-dependent probe amplification (MLPA) that permits the screening of different loci, such as subtelomeric sequences in one experiment, but is not suitable for genome-wide screening [Gijsbers and Ruivenkamp, 2011]. Different array-based techniques have been used to analyze the whole genome and to detect clinically relevant genomic imbalances [ $\mathrm{Lu}$ et al., 2007; Koolen et al., 2009]. These techniques have allowed discovering novel microdeletion and microduplication syndromes, making a more precise determination of breakpoints, better establishment of genotypephenotype associations, identifying genes relevant to a given phenotype as well as elucidating the mechanisms involved in the chromosome aberrations [Mencarelli et al., 2008; Slavotinek, 2008; Miller et al., 2010]. Some chromosome alterations, when investigated by refined techniques such as arrays, have shown an unexpected rate of complexity, as seen in cases of marker chromosomes

\section{KARGER \\ Fax +4161306 1234 \\ E-Mail karger@karger.ch}

www.karger.com
(C) 2012 S. Karger AG, Basel

$1661-8769 / 12 / 0031-0039 \$ 38.00 / 0$

Accessible online at:

www.karger.com/msy
Maria Isabel Melaragno

Department of Morphology and Genetics, Universidade Federal de São Paulo Rua Botucatu 740

São Paulo, SP 04023-900 (Brazil)

Tel. +55 115576 4260, E-Mail melaragno.morf@epm.br 
[Baldwin et al., 2008], ring chromosomes [Vazna et al., 2008], and apparently balanced translocations [Gu et al., 2008]. Slavotinek [2008], for instance, states that array techniques have given rise to 'reverse dysmorphology', a new approach by which identification of a cytogenetic/ genomic alteration precedes the corresponding definition of the clinical phenotype. Thus, the use of array techniques to detect chromosome abnormalities in patients with mental retardation and congenital abnormalities has increased diagnostic success with major implications for clinical practice.

\section{Patient and Methods}

\section{Patient}

The index patient, a boy, the first child of young nonconsanguineous parents, was born at term after an uneventful pregnancy. Birth weight was 2,805 g (10-25th centile), length $48 \mathrm{~cm}$ (10-25th centile), OFC not recorded. Laryngomalacia was diagnosed at birth. At 5 months of age, he presented a cervical lymphangioma. His developmental progress was not delayed (he was able to sit unassisted at 6 months, walk at 15 months, and talk at 12 months of age). Renal ultrasound and echocardiogram were normal, and a brain tomography revealed mild frontal cerebral atrophy and Dandy-Walker variant. At 14 months of age (fig. 1A), the patient's weight was $7 \mathrm{~kg}$ (3rd centile), height 69.5 $\mathrm{cm}$ (2nd centile) and head circumference $44.5 \mathrm{~cm}$ (5th centile). He showed a glabellar hemangioma, sparse eyebrows, downslanting palpebral fissures, epicanthic folds, long eyelashes, a nose with a depressed bridge and bulbous tip, low-set and rotated ears, long fingers, clinodactyly of the fifth fingers and persistent fetal fingertip pads. A clinical reevaluation at 27 months of age revealed that the glabellar hemangioma had disappeared and the patient's facial features had become more pronounced. Written informed consent for the study was obtained from the patient's legal guardians.

Classical and Molecular Cytogenetic Analyses

Chromosome analysis with G-banding was performed on 72-h lymphocyte cultures according to standard procedures. FISH was performed using commercial Y-centromeric and SRY probes (Cytocell, Cambridge, UK) as well as the RP11-669F13 (4q28.1) BAC probe, as previously reported [Kulikowski et al., 2006].

\section{Molecular Studies}

DNA was isolated from peripheral blood using the Gentra Puregene kit (Qiagen Sciences, Germantown, Md., USA). A MLPA assay was performed using the $\mathrm{P} 070$ human telomere 5 probemix kit (MRC-Holland, Amsterdam, The Netherlands) and analyzed using the GeneMarker ${ }^{\circledR}$ software (SoftGenetics, LLC, State College, Pa., USA). Samples were genotyped using the Genome-Wide Human SNP Array 6.0 and data were analyzed with the Chromosome Analysis Suite (ChAS) Software (Affymetrix Inc., Santa Clara, Calif., USA), using annotation GRCh37/hg19.

\section{Results}

The cytogenetic analysis of the patient revealed a complex karyotype with an interstitial deletion of the long arm of chromosome 4 along with a small Y-chromosome, different from his father's (fig. 1B, C). MLPA analysis showed 3 copies of the pseudoautosomal region 1 (PAR1) and 1 copy of the pseudoautosomal region 2 (PAR2) of the X/Y-chromosomes (data not shown). SNP-array analysis revealed a $\sim 24-\mathrm{Mb}$ interstitial deletion at $4 \mathrm{q} 26$ to $4 q 31.1$, ranging from $116,804,645$ to $141,102,956$ bp (fig. 1E), and a duplication of the short arm and of a segment of the long arm of the Y-chromosome sized up to $15,982,252$ bp (Yq11.221), along with a 15,989,842-bp deletion of the long arm of the Y-chromosome (Yq11.221) (fig. 1D). FISH performed on interphase nuclei using a Ycentromeric probe showed 2 signals (fig. 1F), while the $S R Y$ probe used on metaphase chromosomes showed 2 signals on the Y-chromosome, one on each arm (fig. 1G). FISH using the RP11-669F13 probe confirmed the 4q deletion (fig. $1 \mathrm{H}$ ). The parents' karyotypes were normal.

Thus, the patient's karyotype, as revealed by cytogenetic and molecular methods, is 46,XY,idic(Y)(q11.221),

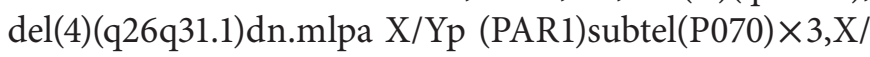
Yq(PAR2)subtel(P070) $\times 1$.arr XYPAR1 $(168,464-2,693,624)$ $\times 3$,Yp11.31q11.221 $(2,650,426-15,982,252) \times 2$,Yq11.221q12 $(15,989,842-28,799,924) \times 0,4 q 26 q 31.1(116,804,645-$ $141,102,956) \times 1$.

\section{Discussion}

We report here a complex de novo chromosome rearrangement consisting of an interstitial $24 \mathrm{Mb} 4 \mathrm{q}$ deletion and an isodicentric Y. Isodicentric Y-chromosomes represent the most common structural abnormality of the Y-chromosome [Hsu, 1994]. The phenotypes of individuals carrying them vary from typical Turner syndrome to phenotypic males and to ambiguous genitalia, depending on the location of the breakpoints and on the proportion of each cell line [DesGroseilliers et al., 2006]. Our patient, at clinical reevaluation, has normal male genitalia. Literature reports show that individuals with 2 copies of the $S R Y$ gene usually develop as males, although infertile, due to the absence of one of the azoospermia factor (AZF) regions [Chandley et al., 1986]. The AZF, located in the long arm of the Y-chromosome, is associated with spermatogenesis and comprises 3 different regions (AZFa, AZFb and AZFc) [Vogt et al., 1996; Shi et al., 2010]. Deletions of any individual or multiple AZF region(s) can 


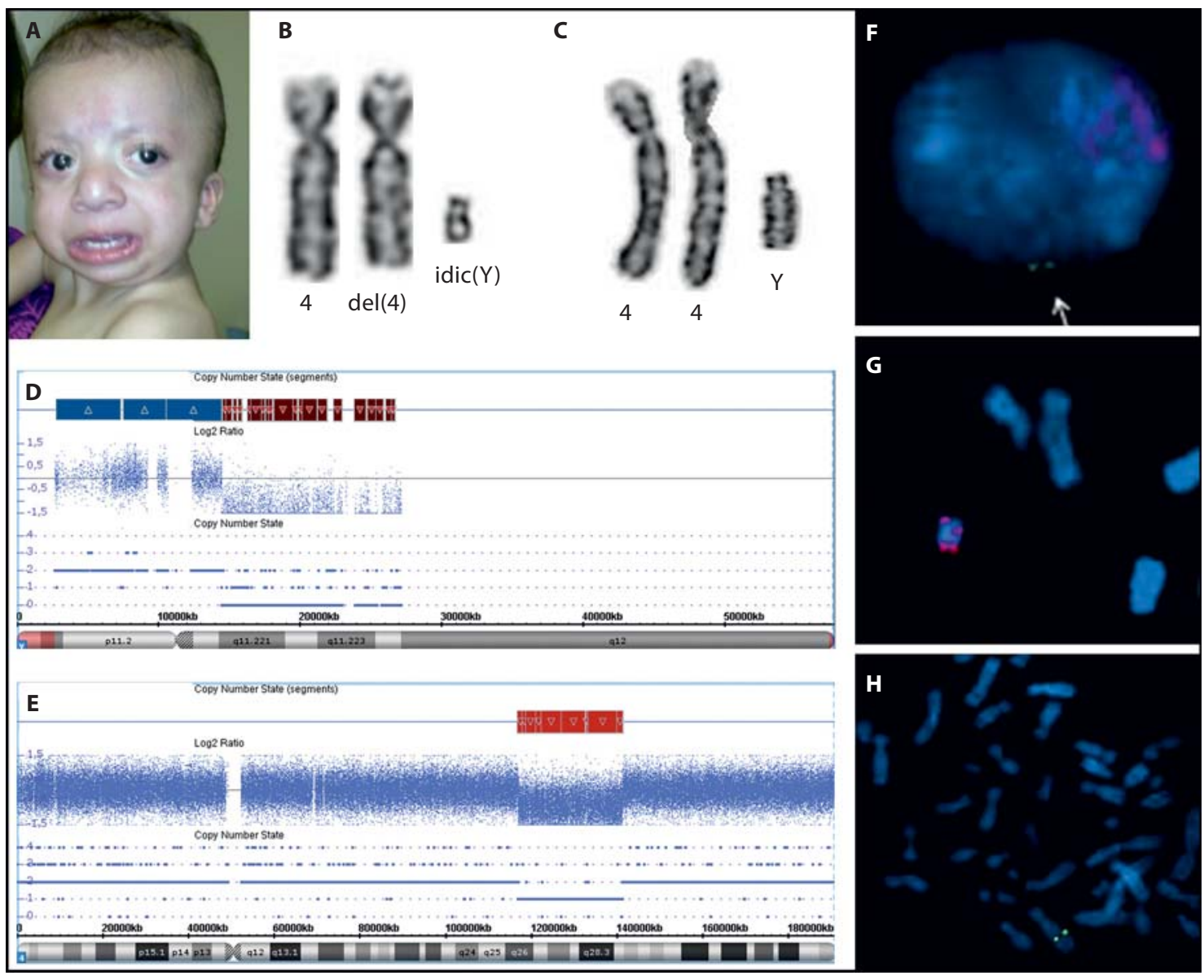

Fig. 1. A Patient at the age of 14 months. B Partial karyotype of the patient showing the del(4)(q26q31.1) and the $\operatorname{idic}(Y)(q 11.221)$. C Partial karyotype of his father showing chromosome pair 4 and the Y-chromosome. D Array images of the patient's Y-chromosome showing the duplicated region (blue) and the missing region (red). E Chromosome 4 showing the deleted region (red). F FISH with a centromeric probe for the Y-chromosome showing 2 hybridization signals (arrow) on an interphase nucleus. G An SRY gene probe showing 2 signals on the $\operatorname{idic}(\mathrm{Y})$. H FISH with the RP11-669F13 probe, showing a signal only on the normal chromosome 4.

cause infertility associated with azoospermia to oligozoospermia [Shi et al., 2010]. The main candidate for causing infertility in $\mathrm{AZFb}$ is the RBMY gene (OMIM 400006), while in the AZFc region, the AZF region most frequently deleted in infertile males, it is the $D A Z$ (deleted in azoospermia) gene (OMIM 400003) [Mahadevaiah et al., 1998]. Our patient presents an idic(Yp) with 2 copies of $S R Y$, but no copy of Yq11.221 to Yq12, that includes the AZFb and AZFc regions. Fertility could not be evaluated because of the patient's age, but, considering the segment deleted in the Y-chromosome, it is very likely that he will be infertile.

The Y-chromosome includes the male-specific Y region $(95 \%$ of the euchromatic region of the Y-chromo- some) flanked by 2 pseudoautosomal regions (5\%). In our patient, the idic(Yp) presents a duplication of PAR1 and a deletion of PAR2. The function of most PAR genes is unknown, making it difficult to affirm whether a patient's phenotype is correlated with changes in these regions. The SHOX gene is the best-established disease locus in PAR1 and heterozygous deletions of 2 distinct regions of the PAR1; small insertions or deletions mutations in SHOX gene and alterations in its downstream enhancer region have been found in more than $60 \%$ of patients with LériWeill dyschondrosteosis, in 2-15\% of idiopathic short stature cases, and in $100 \%$ of patients with Langer mesomelic dysplasia [Benito-Sanz et al., 2006; Huber et al, 2006; Jorge et al., 2007; Chen et al., 2009; Hirschfeldova et al., 2012]. 
There is a controversy about the influence of SHOX and its enhancer's duplication in height abnormalities. Patients with duplications including the SHOX gene were reported to present height above, below or within the normal range [Thomas et al, 2009; Benito-Sanz et al., 2011; Jorgez et al., 2011]. Based on the largest number of SHOX duplications to date, Benito-Sanz et al. [2011] showed that partial SHOX duplications appear to be more deleterious than complete SHOX duplications.

Our patient, who presents with short stature, has a homogeneous idic(Y), compatible with a mechanism of formation involving a break and reunion of the sister chromatids at the same locus [Xu and Siu, 2010]. This idic(Y) was present in all 40 metaphases analyzed, indicating stability of the abnormal chromosome. Bergeron et al. [2011] suggested that the intercentromeric distance has a negative influence on the stability of $\operatorname{idic}(\mathrm{Y})$, since a greater proportion of cells with breakage or loss of the idic $(\mathrm{Y})$ were found in $\operatorname{idic}(\mathrm{Y})$ cases with a greater intercentromeric distance. In fact, our patient presents the smallest intercentromeric distance compared to the $10 \mathrm{idic}(\mathrm{Y}) \mathrm{pa}-$ tients reported by Bergeron et al. [2011]. Interstitial deletions of the long arm of chromosome 4 are not often reported in the literature. The deleted genomic interval $4 \mathrm{q} 24 \mathrm{q} 31.3$ in our patient encompasses 40 OMIM genes and 28 other genes. Three of them could be associated with the cervical lymphagioma found in the patient. The FGF2 (Fibroblast Growth Factor 2 - OMIM 134920) gene is a wide-spectrum mitogenic, angiogenic, and neurotrophic factor [Bikfalvi et al., 1997]. Elevated levels of FGF2 are associated with the proliferation of smooth muscle in atherosclerosis and with the proliferation of tumors. Another gene that could be correlated with the patient's phenotype is NUDT6 (Nucleoside DiphosphateLinked Moiety X Motif 6 - OMIM 606261), an FGF2 antisense gene that may regulate its expression. The third gene involved with tumorigenesis is SPRY1 (a homologue of the Drosophila Sprouty 1 - OMIM 602465), which produces a protein that acts as a negative feedback loop to modulate the RTK/Ras/MAPK pathway and can function as a tumor suppressor [Lo et al., 2006]. In addition, Sprouty genes are differentially expressed in hepatocellular carcinoma [Sirivatanauksorn et al., 2011], indicating their role in carcinogenesis. The neurotrophic function of the FGF2 gene may also have contributed to our patient's mild frontal cerebral atrophy and Dandy-Walker variant, revealed by brain tomography. Fgf2 knockout mice revealed abnormalities in the cytoarchitecture of the neocortex, most pronounced in the frontal motorsensory area, with a significant reduction in neuronal density, indicating that $F G F 2$ plays a specific role in cortical neurogenesis [Ortega et al., 1998]. Moreover, Fgf2-deficient mice show neuronal defects in the cerebral cortex, hippocampal commissure and spinal cord [Dono et al., 1998]. The NAA15 gene (N-alpha-acetyltransferase 15 OMIM 608000), which is deleted in our patient, could also explain his neuronal alterations. Studies in mice indicate that this gene is highly expressed in areas of cell division and migration, and its expression appears to be downregulated as neurons differentiate, suggesting that it plays a role in the generation and differentiation of neurons [Sugiura et al., 2001, 2003]. Other genes located in the deleted region of chromosome 4 have been associated with susceptibility to some diseases, such as diabetes, celiac disease, autoimmune diseases, among others, which should be carefully investigated in this patient in order to prevent them or treat them early. Thus, the patient's phenotype is due to both alterations found in the complex karyotype with an interstitial deletion in $4 \mathrm{q}$ and a heterogeneous idic(Y) with PAR1 duplication and PAR2 deletion. This patient (No. 261263), registered in DECIPHER (Database of Chromosomal Imbalance and Phenotype in Humans using Ensembl Resources (https://decipher. sanger.ac.uk)), to our best knowledge, is the only case in the literature with a deletion encompassing the region from $4 \mathrm{q} 26$ to $4 \mathrm{q} 31.1$.

\section{Acknowledgement}

This work was supported by CAPES and FAPESP (Brazil).

References

Baldwin EL, May LF, Justice AN, Martin CL, Ledbetter DH: Mechanisms and consequences of small supernumerary marker chromosomes: from Barbara McClintock to modern genetic-counseling issues. Am J Hum Genet 82:398-410 (2008).

-Benito-Sanz S, del Blanco DG, Aza-Carmona M, Magano LF, Lapunzina P, et al: PAR1 deletions downstream of SHOX are the most frequent defect in a Spanish cohort of LériWeill dyschondrosteosis (LWD) probands. Hum Mutat 27:1062 (2006).

-Benito-Sanz S, Barroso E, Heine-Suñer D, Hisado-Oliva A, Romanelli V, et al: Clinical and molecular evaluation of SHOX/PAR1 duplications in Léri-Weill dyschondrosteosis (LWD) and idiopathic short stature (ISS). J Clin Endocrinol Metab 96:E404412 (2011). 
-Bergeron MB, Brochu P, Lemyre E, Lemieux N: Correlation of intercentromeric distance, mosaicism, and sexual phenotype: molecular localization of breakpoints in isodicentric Y chromosomes. Am J Med Genet A 155A:2705-2712 (2011).

-Bikfalvi A, Klein S, Pintucci G, Rifkin DB: Biological roles of fibroblast growth factor-2. Endocr Rev 18:26-45 (1997).

-Chandley AC, Ambros P, McBeath S, Hargreave TB, Kilanowski F, Spowart G: Short arm dicentric $\mathrm{Y}$ chromosome with associated statural defects in a sterile man. Hum Genet 73: 350-353 (1986).

-Chen J, Wildhardt G, Zhong Z, Röth R, Weiss B, et al: Enhancer deletions of the SHOX gene as a frequent cause of short stature: the essential role of a $250 \mathrm{~kb}$ downstream regulatory domain. J MedGenet 46:834-839 (2009).

-DesGroseilliers M, Beaulieu Bergeron M, Brochu P, Lemyre E, Lemieux N: Phenotypic variability in isodicentric $Y$ patients: study of nine cases. Clin Genet 70:145-150 (2006).

-Dono R, Texido G, Dussel R, Ehmke H, Zeller R: Impaired cerebral cortex development and blood pressure regulation in $\mathrm{Fgf2}$-deficient mice. EMBO J 17:4213-4225 (1998).

Gijsbers AC, Ruivenkamp CA: Molecular karyotyping: from microscope to SNP arrays. Horm Res Paediatr 76:208-213 (2011).

- Gu W, Zhang F, Lupski JR: Mechanisms for human genomic rearrangements. Pathogenetics 1:4 (2008)

-Hirschfeldova K, Solc R, Baxova A, Zapletalova J, Kebrdlova V, et al: SHOX gene defects and selected dysmorphic signs in patients of idiopathic short stature and Léri-Weill dyschondrosteosis. Gene 491:123-127 (2012).

-Hsu LY: Phenotype/karyotype correlations of Y chromosome aneuploidy with emphasis on structural aberrations in postnatally diagnosed cases. Am J Med Genet 53:108-140 (1994).

-Huber C, Rosilio M, Munnich A, Cormier-Daire V; French SHOX GeNeSIS Module: High incidence of SHOX anomalies in individuals with short stature. J Med Genet 43:735-739 (2006).
Jorge AA, Souza SC, Nishi MY, Billerbeck AE, Libório DC, et al: SHOX mutations in idiopathic short stature and Léri-Weill dyschondrosteosis: frequency and phenotypic variability. Clin Endocrinol (Oxf) 66:130-135 (2007).

Jorgez CJ, Weedin JW, Sahin A, Tannour-Louet $\mathrm{M}, \mathrm{Han}$ S, et al: Aberrations in pseudoautosomal regions (PARs) found in infertile men with Y-chromosome microdeletions. J Clin Endocrinol Metab 96:E674-679 (2011).

Koolen DA, Pfundt R, de Leeuw N, Hehir-Kwa JY, Nillesen WM, et al: Genomic microarrays in mental retardation: a practical workflow for diagnostic applications. Hum Mutat 30:283-292 (2009)

Kulikowski LD, Christ LA, Nogueira SI, Brunoni D, Schwartz S, Melaragno MI: Breakpoint mapping in a case of mosaicism with partial monosomy 9p23 $\rightarrow$ pter and partial trisomy $1 \mathrm{q} 41 \rightarrow$ qter suggests neo-telomere formation in stabilizing the deleted chromosome. Am J Med Genet A 140:82-87 (2006).

Lo TL, Fong CW, Yusoff P, McKie AB, Chua MS, et al: Sprouty and cancer: the first terms report. Cancer Lett 242:141-150 (2006).

Lu W, van Eerde AM, Fan X, Quintero-Rivera F, Kulkarni S, et al: Disruption of $\mathrm{ROBO} 2$ is associated with urinary tract anomalies and confers risk of vesicoureteral reflux. Am J Hum Genet 80:616-632 (2007)

Mahadevaiah SK, Odorisio T, Elliott DJ, Rattigan A, Szot M, et al: Mouse homologues of the human AZF candidate gene RBM are expressed in spermatogonia and spermatids, and map to a Y chromosome deletion interval associated with a high incidence of sperm abnormalities. Hum Mol Genet 7:715-727 (1998).

- Mencarelli MA, Katzaki E, Papa FT, Sampieri K, Caselli R, et al: Private inherited microdeletion/microduplications: implications in clinical practice. Eur J Med Genet 51:409416 (2008).

Miller DT, Adam MP, Aradhya S, Biesecker LG, Brothman AR, et al: Consensus statement: chromosomal microarray is a first-tier clinical diagnostic test for individuals with developmental disabilities or congenital anomalies. Am J Hum Genet 86:749-764 (2010).
Ortega S, Ittmann M, Tsang SH, Ehrlich M, Basilico C: Neuronal defects and delayed wound healing in mice lacking fibroblast growth factor 2. Proc Natl Acad Sci USA 95: 5672-5677 (1998).

-Shi YC, Cui YX, Zhou YC, Wei L, Jiang HT, et al: A rare $\mathrm{Y}$ chromosome constitutional rearrangement: a partial $\mathrm{AZFb}$ deletion and duplication within chromosome Yp in an infertile man with severe oligoasthenoteratozoospermia. Int J Androl 34:461-469 (2010).

-Sirivatanauksorn Y, Sirivatanauksorn V, Srisawat C, Khongmanee A, Tongkham C: Differential expression of sprouty genes in hepatocellular carcinoma. J Surg Oncol 105:273276 (2012).

-Slavotinek AM: Novel microdeletion syndromes detected by chromosome microarrays. Hum Genet 124:1-17 (2008).

-Sugiura N, Patel RG, Corriveau RA: N-methyl$\mathrm{D}$-aspartate receptors regulate a group of transiently expressed genes in the developing brain. J Biol Chem 276:14257-14263 (2001).

Sugiura N, Adams SM, Corriveau RA: An evolutionarily conserved $\mathrm{N}$-terminal acetyltransferase complex associated with neuronal development. J Biol Chem 278:40113-40120 (2003).

Thomas NS, Harvey JF, Bunyan DJ, Rankin J, Grigelioniene G, et al: Clinical and molecular characterization of duplications encompassing the human SHOX gene reveal a variable effect on stature. Am J Med Genet A 149A:1407-1414 (2009).

- Vazna A, Havlovicova M, Sedlacek Z: Molecular cloning and analysis of breakpoints on ring chromosome 17 in a patient with autism. Gene 407:186-192 (2008).

Vogt PH, Edelmann A, Kirsch S, Henegariu O, Hirschmann P, et al: Human Y chromosome azoospermia factors (AZF) mapped to different subregions in Yq11. Hum Mol Genet 5: 933-943 (1996).

Xu J, Siu VM: Is there a correlation between the proportion of cells with isodicentric Yp at amniocentesis and phenotypic sex? Prenat Diagn 30:839-844 (2010). 